\title{
Novel evidence indicates the presence and replication of hepatitis $B$ virus in breast cancer tissue
}

\author{
BO QIN $^{1,2}$, KAITAO ZHAO $^{2}$, JIANGUO WEI $^{1}$, XIN WANG $^{1}$, MINJUN XU $^{1}$, \\ JUAN LANG $^{1}$, HONGGANG SUN ${ }^{1}$ and KETAO JIN ${ }^{1}$ \\ ${ }^{1}$ Shaoxing People's Hospital, The First Affiliated Hospital of Shaoxing University, Shaoxing, \\ Zhejiang 312000; ${ }^{2}$ State Key Laboratory of Virology, Wuhan Institute of Virology, \\ Chinese Academy of Sciences, Wuhan, Hubei 430071, P.R. China \\ Received February 11, 2019; Accepted October 1, 2019
}

DOI: $10.3892 /$ or.2019.7393

\begin{abstract}
As a member of the liver tropic virus family, hepatitis B virus (HBV) was thought to only infect and replicate within the liver. Sodium taurocholate co-transporting polypeptide (NTCP) has been identified as a functional cellular receptor and a major determinant of liver tropism and HBV entry level species specificity. In the present study, the Oncomine database was used to explore differences in NTCP expression among cancerous and normal tissues. The results revealed that NTCP was highly expressed in breast cancer (BC), which was subsequently verified in clinical samples. Furthermore, in the BC tissue of patients with chronic HBV, HBV antigens, viral DNA/RNA and specific viral particles were detected via immunohistochemistry, ELISA, western blotting, reverse transcription-quantitative PCR and electron microscopy. Different HBV biomarkers and Dane particles were detected in BC. Furthermore, high levels of HBV-specific RNAs, the characteristic signals of HBV replication, were also detected, indicating that $\mathrm{HBV}$ infects $\mathrm{BC}$ tissue by binding to NTCP and replicating within. Based on the data of the present study, BC tissue may represent a second location of HBV infection and replication in addition to the liver.
\end{abstract}

\section{Introduction}

Human hepatitis B virus (HBV) is a key cause of chronic hepatitis, liver cirrhosis and hepatocellular carcinoma (HCC) (1). Despite an effective vaccine being readily available, no effective therapies are able to completely remove HBV and as such, approximately 1 million new infections occur yearly, with approximately 240 million chronic HBV

Correspondence to: Professor Bo Qin, Shaoxing People's Hospital, The First Affiliated Hospital of Shaoxing University, 568 Zhongxing North Road, Shaoxing, Zhejiang 312000, P.R. China

E-mail: qinbo0809@hotmail.com

Key words: hepatitis B virus, sodium taurocholate cotransporting polypeptide, breast cancer, liver tropism
(CHB) infections worldwide (2). Compared with uninfected individuals, $\mathrm{HBV}$-infected patients have a 100 -fold-increased risk of $\mathrm{HCC}$ and more than $50 \%$ of $\mathrm{HCC}$ cases are attributed to $\mathrm{HBV}$ infection (3). HBV-associated liver diseases remain a major public health issue, causing an estimated one million deaths per year in China (4).

Despite partial elucidation of the underlying mechanisms of HBV since its discovery 50 years ago, many elements of HBV remain unclear, including the detailed mechanism of liver tropism and its species specificity (5). HBV enters liver cells by binding to surface receptors subsequent to engulfment (6). Recent research has revealed that sodium taurocholate co-transporting polypeptide (NTCP) is a functional receptor of $\mathrm{HBV}$ and hepatitis D virus (HDV) infection, a fact which has increased the understanding of early infection and species tropism (6). NTCP-mediated HBV entry interferes with bile acid transport and is associated with alterations in bile acid and cholesterol metabolism. Infection efficiency of HBV in certain hepatoma cell lines, such as HepG2 and Huh7D, is enhanced and has been reported to support the life cycle of HBV via NTCP. This has provided a platform for studies of the basic biology of HBV and anti-HBV treatments $(7,8)$. Juvenile human NTCP transgenic mice are susceptible to HDV (9). Myrcludex-B and vanitaracin A specifically target NTCP and efficiently inhibit HBV entry $(10,11)$. The liver was previously thought to be the sole target of HBV and HDV; the entry-level barrier, the special atmosphere of the human liver and some unknown reasons prevent cross-species and cross-liver infection with HBV (12). This is also the reason why we call them hepatotropic viruses. The specific liver tropism of HBV/HDV infection, so far as is known, is the first determined at entry level, in which NTCP serves a key role (5).

The Oncomine Platform provides solutions for researchers with robust, peer-reviewed analytical methods (13). In the present study, Oncomine was used to determine the differences in NTCP expression among cancerous and normal tissues. The results revealed that NTCP is overexpressed in breast cancer (BC) compared with normal breast tissue. Subsequent to this result, the present study assessed the association of HBV and BC. The RNA and protein levels of NTCP were screened in liver cancer, $\mathrm{BC}$ and their corresponding para-carcinoma tissues. It was determined that NTCP was highly expressed in 
$\mathrm{BC}$, liver cancer and paracancerous liver tissues. Furthermore, specific HBV antigens, along with viral DNA/RNA and Dane particles were identified in $\mathrm{BC}$ tissue of $\mathrm{CHB}$ female patients. $\mathrm{HBV}$ was able to successfully infect $\mathrm{BC}$ tissue and replicate within by binding to NTCP. The results revealed that in addition to the liver, which was considered to be the only organ to support the HBV life cycle, BC tissue may be a second site of HBV reproduction.

\section{Materials and methods}

Patients and cell lines. The serum and pathological tissues of patients between 2013 and 2017 was collected, and HBV DNA was isolated using a QIAamp DNA Blood Mini kit (Qiagen) (14). Through the use of hospital software databases [LIS (Beijing Zhifang, China) and HIS (Hua wei zhong bang, Shaoxing, Zhejiang, China)] of Shaoxing Hospital, historical pathological materials including paraffin-embedded breast neoplasms and fresh pathological tissues from chronic hepatitis $\mathrm{B}(\mathrm{CHB})\left(\mathrm{HBV}^{+}\right)$and $\mathrm{HBV}$-negative $\left(\mathrm{HBV}^{-}\right)$patients were retrospectively and prospectively acquired from the Department of Pathology, Shaoxing People's Hospital (Table I). Follow-up data were obtained and patient informed consent was provided. The present study was conducted in compliance with the ethical guidelines of the 1975 Declaration of Helsinki and was approved by the Ethics Committee of Shaoxing People's Hospital (2019 Ethics clearance no. 03).

Huh7-NTCP, Huh7, HepG2, HepG2.2.15 and 293T cell lines were kindly provided by Professor Xinwen Chen (Wuhan Institute of Virology, Chinese Academy of Sciences, Wuhan, China). MCF-7 and MDA-MB-231 cell lines were purchased from the Cell Bank of Chinese Academy of Medical Science (Shanghai, China). The cells were maintained in DMEM (Invitrogen; Thermo Fisher Scientific, Inc.) supplemented with 10\% FBS (Gibco; Thermo Fisher Scientific, Inc.), 2 mM/1 glutamine, $100 \mathrm{IU} / \mathrm{ml}$ penicillin and $100 \mathrm{IU} / \mathrm{ml}$ streptomycin, at $37^{\circ} \mathrm{C}$ in a moist environment containing $5 \% \mathrm{CO}_{2}$.

Preparation of primary $\mathrm{BC}$ cells. Breast tumors from $\mathrm{HBV}^{+}$ and control $\mathrm{HBV}^{-}$patients were respectively collected, along with follow-up data. Tissues were selectively cut and washed three times with PBS (100 IU/ml penicillin and $100 \mathrm{IU} / \mathrm{ml}$ streptomycin). Tissues $(\sim 1,000 \mathrm{mg})$ were washed and cut into pieces using a sterile surgical scissor and tweezer, and transferred to $50-\mathrm{ml}$ sterile centrifuge tubes containing $10 \mathrm{ml} 0.2 \%$ collagenase IV for digestion at $37^{\circ} \mathrm{C}$ for $3 \mathrm{~h}$ with shaking $(100 \mathrm{rpm})(15,16)$. Single cells were obtained via a 100 mesh cell strainer and centrifuged at 1,000 RCF for $5 \mathrm{~min}$. Samples were then resuspended in DMEM as previously described (17). Primary culture breast tumor cells were subsequently plated in culture flasks/plates in DMEM and incubated at $37^{\circ} \mathrm{C}$ in a $5 \%$ $\mathrm{CO}_{2}$ atmosphere as previously described (14).

Electron microscopy (EM). The $\mathrm{BC}$ tissues of $\mathrm{HBV}^{+/}$patients were obtained from the Pathology Department of Shaoxing People's Hospital (Shaoxing, China). After washing with pre-cooling PBS buffer, the tissue in mung bean size $(4-5 \mathrm{~mm})$ was fixed and stored in $2.5 \%$ glutaraldehybe solution stationary liquid (Solarbio). Samples were visualized using a Tecnai G ${ }^{2}$ F20 S-TWIN (FEI; Thermo Fisher Scientific, Inc.) transmission electron microscope at an acceleration voltage of $200 \mathrm{kV}$ with 1.05 M fold maximum magnification (18).

ELISA. Hepatitis B surface antigen (HBsAg) and hepatitis B e antigen $(\mathrm{HBeAg})$ are two important makers of HBV that are found in the supernatants of BC primary culture cells and/or patient serum. These were detected in the present study using Diagnostic kits for HBsAg and HBeAg (Kehua, Shanghai) in accordance with the manufacturer's protocol and as previously described (4).

Detection of virion-associated HBV DNA. Encapsidated HBV replicative intermediates were purified and subjected to Southern blot analysis as described previously (14). Isolated HBV DNA was subjected to agarose gel electrophoresis, followed by denaturation and Southern blotting. HBV DNA was detected by hybridization with a ${ }^{32} \mathrm{P}$-labeled full length HBV probe (14). Hybridization signals were visualized and analyzed using a Phospho-Imager (Cyclon, Parkard). Data were quantified using its own Optiquant software. HBV DNA was also quantified by performing quantitative PCR using a TaqMan probe (Probe-HBV) and primers (Primer-HBV-S-F and Primer-HBV-S-R; Table II) (19). To perform PCR according to the manufacturer's protocol, HBV DNA was extracted from $600 \mu \mathrm{l}$ of serum or cell-cultured supernatant using a DNA Extraction Reagent of HBV Fluorescence Quantitative Polymerase Chain Reaction kit (Fosun Pharma Diagnostics, China). Furthermore, viral and genomic DNA was extracted from $50 \mathrm{mg}$ of $\mathrm{BC}$ tissue (stored in liquid nitrogen) using the DNeasy Blood \& Tissue kit (Qiagen) as previously described (20). Extracted DNA (20 $\mu \mathrm{l})$ was used as a template and was mixed with $30 \mu \mathrm{l}$ PCR Master Mix (Fosun Pharma Diagnostics), containing tricine buffer, potassium hydroxide, dNTPs, HBV-specific primers and fluorescent-labeled oligonucleotide probes. The reaction was performed using a LightCycler 480 PCR apparatus (Hoffman-La Roche Ltd., Basel, Switzerland). All samples were analyzed in triplicate.

Quantification of the RNA level of HBV, NTCP and heparan sulfate proteoglycan (HSPG) by reverse transcription-quantitative $(R T-q) P C R$. Total RNA was extracted from different tissues (200 mg liver, BC or other tissues) or cells $\left(1 \times 10^{6}\right)$ using TRIzol (cat. no. 113702; Life Technologies). After performing a genomic DNA elimination reaction using gDNA Eraser, cDNA was synthesized from extracted RNA using the PrimeScript ${ }^{\mathrm{TM}}$ RT reagent kit with gDNA Eraser (Takara, Japan) (21). According to the manufacturer's protocol, HBV cDNA, NTCP and HSPG were amplified with specific primers (Table II) using the LightCycler 480 PCR apparatus (Hoffman-La Roche Ltd.) (22). Levels of NTCP and HSPG relative to $\beta$-actin were evaluated using the $2^{-\Delta \Delta \mathrm{Cq}}$ method (13). Following reverse transcription, HBV RNA levels were analyzed using the same method of virion-associated HBV DNA detection as aforementioned. All samples were analyzed in triplicate.

Western blotting. After washing with $\mathrm{PBS}$ at $4^{\circ} \mathrm{C}$, the cell lines used in the present study were lysed with cell lysis buffer (cat. no. P0013B; Beyotime Institute of Biotechnology) and inhibitors of proteases (cat. no. 9087-70-1; Solarbio, Beijing, 
Table I. Medical information of the BC patients with HBV infection used in this research.

\begin{tabular}{|c|c|c|c|c|c|}
\hline Patient no. & Gender & Age (years) & HBV infection status & Clinical pathology & HBV DNA titer (IU/ml) \\
\hline 1 & Female & 35 & HBV-Neg & $\mathrm{BC}$ & Undetectable \\
\hline 2 & Female & 62 & HBV-Neg & BBL & Undetectable \\
\hline 3 & Female & 43 & $\mathrm{HBsAg}^{+}$, anti-HBe${ }^{+}$, anti-HBc ${ }^{+}, \mathrm{PreS}^{+}$ & BBL & $8.56 \mathrm{E}+02$ \\
\hline 4 & Female & 52 & $\mathrm{HBsAg}^{+}, \mathrm{PreS}^{-}$ & BBL & Undetectable \\
\hline 5 & Female & 58 & $\mathrm{HBsAg}^{+}, \mathrm{HBeAg}^{+}$, anti-HBc${ }^{+}, \operatorname{PreS} 1^{+}$ & $\mathrm{BC}$ & $7.64 \mathrm{E}+08$ \\
\hline 6 & Female & 48 & $\mathrm{HBsAg}^{+}, \mathrm{HBeAg}^{+}$, anti-HBc ${ }^{+}, \operatorname{PreS} 1^{+}$ & $\mathrm{BC}$ & $3.92 \mathrm{E}+07$ \\
\hline 7 & Female & 39 & $\mathrm{HBsAg}^{+}$, anti-HBe${ }^{+}$, anti-HBc ${ }^{+}, \mathrm{PreS}^{+}$ & BBL & $6.39 \mathrm{E}+04$ \\
\hline 8 & Female & 45 & $\mathrm{HBsAg}^{+}, \mathrm{PreS}^{-}$ & BBL & $5.47 \mathrm{E}^{+} 02$ \\
\hline 9 & Female & 54 & $\mathrm{HBsAg}^{+}, \mathrm{HBeAg}^{+}$, anti-HBc${ }^{+}, \mathrm{PreS}^{+}$ & $\mathrm{BC}$ & $2.35 \mathrm{E}+05$ \\
\hline 10 & Female & 37 & $\mathrm{HBsAg}^{+}$, anti-HBe${ }^{+}$, anti-HBc ${ }^{+}, \mathrm{PreS}^{+}$ & $\mathrm{BC}$ & $7.42 \mathrm{E}+04$ \\
\hline 11 & Female & 49 & HBV-Neg & $\mathrm{BC}$ & Undetectable \\
\hline 12 & Female & 65 & $\mathrm{HBsAg}^{+}$, anti-HBe${ }^{+}$, anti-HBc ${ }^{+}, \mathrm{PreS}^{+}$ & $\mathrm{BC}$ & $1.36 \mathrm{E}+05$ \\
\hline 13 & Female & 45 & $\mathrm{HBsAg}^{+}, \mathrm{PreS}^{+}$ & $\mathrm{BC}$ & Undetectable \\
\hline 14 & Female & 56 & $\mathrm{HBsAg}^{+}, \mathrm{HBeAg}^{+}$, anti-HBc ${ }^{+}, \operatorname{PreS} 1^{+}$ & $\mathrm{BC}$ & $1.04 \mathrm{E}+07$ \\
\hline 15 & Female & 48 & $\mathrm{HBsAg}^{+}$, anti-HBe${ }^{+}$, anti-HBc ${ }^{+}, \mathrm{PreS}^{+}$ & $\mathrm{BC}$ & $2.85 \mathrm{E}+03$ \\
\hline 16 & Female & 36 & $\mathrm{HBsAg}^{+}, \mathrm{PreS}^{-}$ & $\mathrm{BC}$ & Undetectable \\
\hline 17 & Female & 53 & $\mathrm{HBsAg}^{+}, \mathrm{PreS}^{-}$ & $\mathrm{BC}$ & Undetectable \\
\hline 18 & Female & 38 & $\mathrm{HBsAg}^{+}$, anti-HBe${ }^{+}$, anti-HBc ${ }^{+}, \mathrm{PreS}^{+}$ & $\mathrm{BC}$ & $1.38 \mathrm{E}+04$ \\
\hline 19 & Female & 46 & $\mathrm{HBsAg}^{+}$, PreS1$^{-}$ & $\mathrm{BC}$ & Undetectable \\
\hline 20 & Female & 39 & $\mathrm{HBsAg}^{+}$, anti-HBe${ }^{+}$, anti-HBc ${ }^{+}, \mathrm{PreS}^{+}$ & $\mathrm{BC}$ & $7.81 \mathrm{E}+03$ \\
\hline
\end{tabular}

BC, breast cancer; BBL, benign breast lump; First 10 patients are presented in Fig. 5A and B; the last 10 patients are presented in Fig. 5C and D.

Table II. Primer sequences for RT-qPCR.

\begin{tabular}{llc}
\hline Name & \multicolumn{1}{c}{ Sequence $\left(5^{\prime} \rightarrow 3^{\prime}\right)$} & Amplicon size $($ bp) \\
\hline P-HBV-rc-F & GTTGCCCGTTTGTCCTCTAATTC & 100 \\
P-HBV-rc-R & GGAGGGATACATAGAGGTTCCTT & 127 \\
P-NTCP-F & CTGAAGAACATTGAGGCACTGGCCA & \\
P-NTCP-R & TGGAGCAGGTGGTCATCACAATGCT & 115 \\
P-HSPG-F & TTGCTGGTGGAGTTATTGGC & \\
P-HSPG-R & CTGGATGGTTTGCGTTCTAC &
\end{tabular}

HBV-rc-F and P-HBV-rc-R were used in RT-qPCR to detect HBV RC DNA. P-NTCP-F and P-NTCP-R were used to detect NTCP. P-HSPG-F and P-HSPG-R were used for HSPG detection. RT-qPCR, reverse transcription-quantitative PCR; P, primer; rc, relaxed cycle; F, forward; $\mathrm{R}$, reverse; HBV, hepatitis B virus; NTCP, sodium taurocholate co-transporting polypeptide; HSPG, heparan sulfate proteoglycan.

China). Fresh tissues $(\sim 100 \mathrm{mg})$ stored at $-80^{\circ} \mathrm{C}$ were ground in a mortar with liquid nitrogen and transferred to centrifuge tubes, where they were lysed using cell lysis buffer with protease inhibitors. Protein concentrations were determined using a Bio-Rad protein assay kit (Bio-Rad Laboratories, Inc.) as previously described (14). Total cell/tissue lysates $(50 \mu \mathrm{g})$ were subjected to $8 \%$ SDS-PAGE and transferred electrophoretically to a polyvinylidene difluoride membrane. The membrane was blocked with 5\% non-fat milk in PBS with $0.1 \%$ Tween 20 and incubated with primary antibodies against NTCP (Sigma, cat. no. HPA042727, USA) (1:1,000 diluted) and anti- $\beta$-actin (mouse anti-human; cat. no. BS6007M; Bioward Technology) (1:1,000 diluted). After washing three times with
PBST, peroxidase-conjugated secondary goat anti-mouse IgG (Jackson, cat. no. 115-035-003, USA) (1:10,000 diluted) matched to the primary antibodies was added. After further incubation and washing with PBST, targeted proteins were visualized using ECL western blotting detection reagents (GE Healthcare, Little Chalfont, UK), the data were analyzed with ImageJ bundled with 64-bit Java 1.8.0 (23).

Immunohistochemical staining. $\mathrm{BC}$ tissues of $\mathrm{HBV}^{+/-}$patients were obtained from the Pathology Department of Shaoxing People's Hospital (Shaoxing, China). After conventional paraffin embedding and serial sectioning (0.4-0.5 mm/section), $\mathrm{BC}$ tissue slides were heated for deparaffination at $65^{\circ} \mathrm{C}$. 
Endogenous peroxidase activity was then blocked with $3 \%$ hydrogen peroxide for $5 \mathrm{~min}$ and subjected to antigen retrieval at $121^{\circ} \mathrm{C}$ for $90 \mathrm{sec}$ via immersion in $10 \mathrm{mM}$ sodium citrate buffer (pH 6.0). Slides were subsequently washed with PBS and incubated overnight at $4^{\circ} \mathrm{C}$ with anti-HBc or mouse monoclonal antibodies against HBsAg, (cat. nos. B0586 and M3506; Dako, Glostrup, Denmark) (1:1,000 diluted). Sections were incubated with an anti-rabbit HRP-conjugated secondary antibody at room temperature for $60 \mathrm{~min}$. 3,3'-Diaminobenzidine (DAB; cat. no. ZLI-9017; ZSGB-BIO) (1:10,000 diluted) was used for color reaction, with hematoxylin for counterstaining. $\mathrm{HBc} / \mathrm{sAg}$ expression was elevated based on the staining range and the sections of $\mathrm{BC}$ tissues from $\mathrm{HBV}^{-}$patients were used as negative controls. All staining was performed using the Polink-2 Plus ${ }^{\circledR}$ Polymer HRP detection system (ZSGB-BIO) (13).

Statistical analysis. Statistical analysis was performed using GraphPad Prism 5.01 (GraphPad Software, Inc., USA). The results of three independent experiments are presented as the mean \pm standard deviation. Independent-samples were determined using a two-tailed Student's t-test and differences in multiple comparisons were determined using one-way analysis of variance (ANOVA) followed by the Least Significant Difference post hoc test. For all tests, ${ }^{*} \mathrm{P}<0.05,{ }^{* *} \mathrm{P}<0.01$ and ${ }^{* * *} \mathrm{P}<0.001$ were considered to indicate a statistically significant difference.

\section{Results}

NTCP is highly expressed in BC. To determine the expression of NTCP (SLC10A1) in different types of human tissues and its role in HBV infection, Oncomine (https://www.oncomine.org/resource/login.html), a cancer microarray database and web-based data-mining platform, was utilized (13). SLC10A1 was typed into the search box and differential analysis (340 datasets) was selected in the primary filters. 'Cancer vs. Normal analysis' was then selected, after which many datasets appeared. Oncomine data analyses revealed that NTCP expression was highest in liver tissue $(n=8)$ compared with other tissue types (Fig. 1C and D). Furthermore, the NTCP level in breast tissue $(n=13)$ was similar to that of the lung $(n=12)$, esophagus $(n=13)$ and thyroid gland $(n=16)$. When the level of NTCP overexpression was analyzed between normal and corresponding cancer tissues, NTCP expression was revealed to be higher in $\mathrm{BC}$ tissues $(n=53)$ compared with that in normal breast tissue $(n=6)$ (Fig. $1 \mathrm{~A}$ and $\mathrm{B})$.

HSPG is critical for HBV attachment, bringing the virus in close proximity to cell surface NTCP (5). In the present study, we therefore detected the expression of NTCP and HSPG in different human cell lines, paired fresh frozen carcinoma and adjacent tissues. In the cell lines assessed, NTCP mRNA and protein expression was higher in Huh7-NTCP (a stable NTCP cell line) and lower in 293T, MCF-7 and MDA-MB-231 cells. Intermediate levels were observed in hepatocellular carcinoma Huh7 cells and hepatoblastoma HepG2 and HepG2.215 cells (Fig. 2A and C). The differences in HSPG mRNA levels were not significant among the cell lines.

As presented in Fig. 2B and D, the mRNA and protein levels of NTCP were all significantly increased in BC lesions compared with adjacent tissues, which was consistent with the analysis performed by Oncomine. However, no significant differences in liver- and lung-associated tissues were identified. HSPG mRNA levels were similar to those of NTCP and were highly expressed in $\mathrm{BC}$ tissues compared with paracancerous tissues. The high expression of NTCP in BC, a HBV cellular receptor, indicated that $\mathrm{HBV}$ may infect $\mathrm{BC}$ tissue.

$H B s$ and $H B c$ exist in the BC tissue of patients with $C H B$. NTCP has been identified as the cellular receptor of HBV and HDV. In the present study, it was confirmed to be highly expressed in BC. To assess whether HBV replicates in BC, paraffin-embedded breast tumor tissues of $\mathrm{HBV}^{+/-}$patients were collected according to diagnosis and treatment records. Pathological tumor tissues were divided into three groups: BC, para-BC and relatively normal breast. Immunohistochemical (IHC) staining was performed to detect $\mathrm{HBs}$ and $\mathrm{HBc}$ in the paraffin blocks using specific antibodies. As presented in Fig. 3A-F, HBsAg was strongly expressed in the CHD-infected patients with BC, as indicated by red arrows (Fig. 3D-F). Normal tissue sections from $\mathrm{HBV}^{+/}$patients and $\mathrm{BC}$ tissue from $\mathrm{HBV}^{-}$patients were utilized as negative controls (Fig. 3A-C). Furthermore, $\mathrm{HBc}$ and $\mathrm{HBs}$ were detected via IHC in the aforementioned samples (Fig. 3G-L). HBc was markedly expressed in the $\mathrm{BC}$ tissue of $\mathrm{CHB}$ patients (Fig. 3J-L), while negative staining occurred in the normal tissue of $\mathrm{HBV}^{+/-}$patients and in the $\mathrm{BC}$ tissue of $\mathrm{HBV}^{-}$patients (Fig. 3G-I).

Presence of $H B V$ particles in the $B C$ tissues of $C H B$ patients. To search for direct evidence for the existence of $\mathrm{HBV}$ in the $\mathrm{BC}$ tissues of $\mathrm{CHB}$ patients, fresh $\mathrm{BC}$ tissues of $\mathrm{CHB}$ and $\mathrm{HBV}^{-}$patients were obtained and fixed in $2.5 \%$ glutaral for electron microscopic sectioning and electron microscopy (EM). As presented in Fig. 4B-F, sphere particles with a diameter of 20-50 $\mathrm{nm}$ were observed in the BC tissues of 5 CHB patients via Tecnai G ${ }^{2}$ F20 S-TWIN (FEI, USA) transmission electron microscopy. Dane particles of HBV are $42 \mathrm{~nm}$ in size. Most particles labeled by the red arrows in the $\mathrm{BC}$ tissues of CHB patients were of that size (Fig. 4B-F), indicating that $\mathrm{HBV}$ Dane particles were present in the $\mathrm{BC}$ tissues. No specific viral particles were identified in the $\mathrm{BC}$ tissue of $\mathrm{HBV}^{-}$patients and were therefore used as the negative control (Fig. 4A).

$H B V$ core-associated DNA and RNA are located in the BC tissues of $C H B$ patients. Whole genome DNA of breast-associated tissue (wax block) was collected and subjected to Southern blotting or RT-qPCR. A total of 10 wax blocks were utilized in this assay, including $5 \mathrm{BC}$ tissues and 5 benign breast lump (BBL) tissues. The first 2 were $\mathrm{HBV}^{-}$and the remaining 8 were at least $\mathrm{HBsAg}^{+}$. Whole genome DNA was collected and analyzed via Southern blotting. As presented in Fig. 5A, no HBV DNA was detected in the $\mathrm{BC}$ and $\mathrm{BBL}$ tissues of $\mathrm{HBV}^{-}$ patients (lane 1 and 2) or in the three BBLs of patients with CHB (lanes 3, 4 and 8). However, marked HBV replication was observed in four BC samples and one BBL sample of patients with CHB (lane 5, 6, 7, 9 and 10). Before performing Southern blot analysis, all DNA products were detected via RT-qPCR (Fig. 5B), the results of which were in accordance with those of the Southern blotting. 

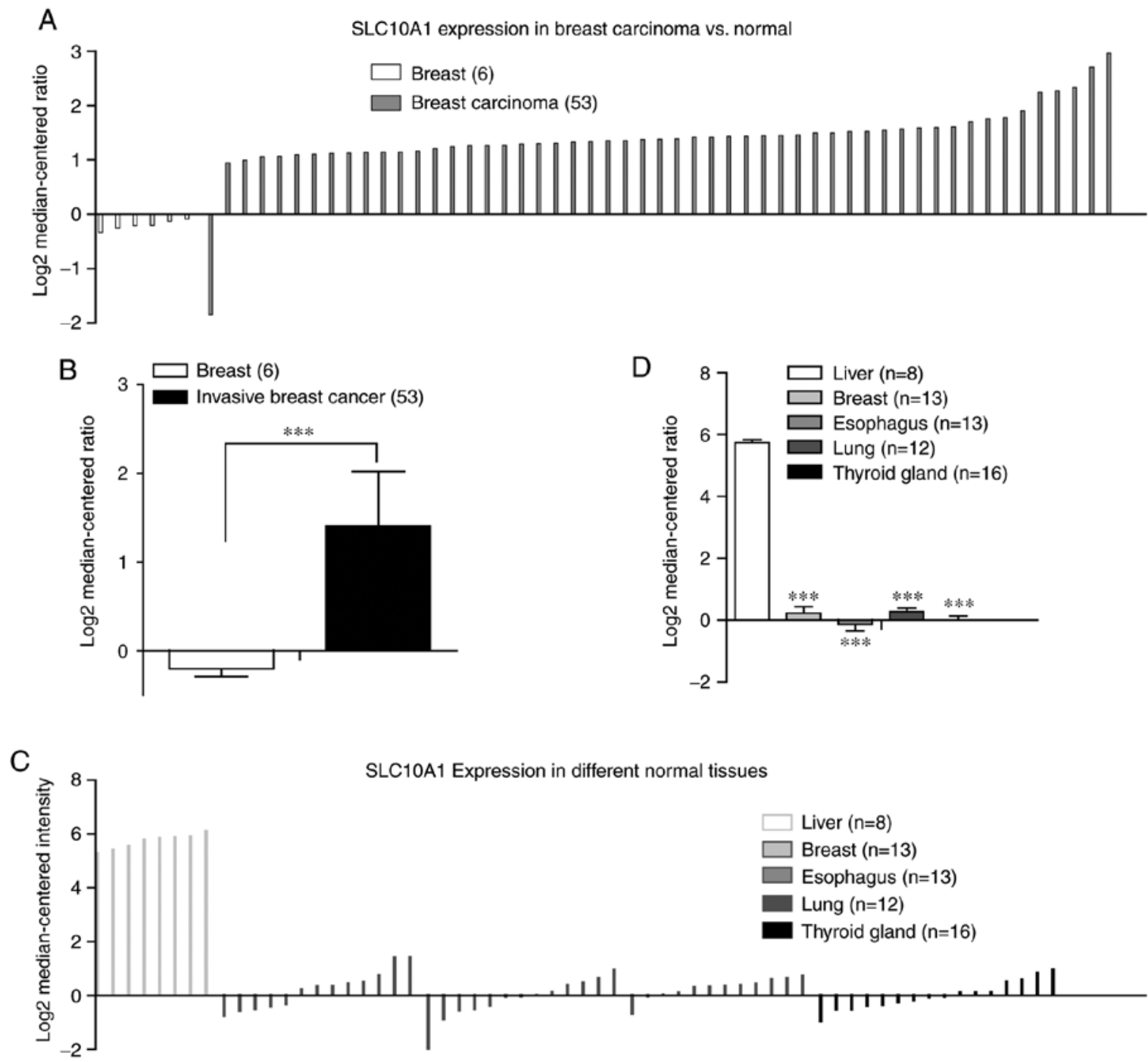

Figure 1. Differential expression of NTCP (SLC10A1) based on Oncomine data. (A) Expression of NTCP in 53 BC tissues and 6 normal breast tissues is presented. (B) Expression difference of NTCP was analyzed. The results revealed that NTCP was markedly upregulated in BC tissue compared with that in normal breast tissues. (C) Expression of NTCP in different human tissues and organs is presented. (D) In addition to the liver, within which NTCP is highly expressed, there were no significant differences in NTCP expression in the breast, lung, esophagus and thyroid gland. ${ }^{* * *} \mathrm{P}<0.001$, with comparisons indicated by brackets. NTCP, sodium taurocholate co-transporting polypeptide; BC, breast cancer.

HBV DNA and RNA was also extracted from fresh BC tissues, para-BC tissues, relatively normal tissues and blood samples of $\mathrm{CHB}$ or $\mathrm{HBV}^{-}$patients. As presented in Fig. 5C, HBV DNA was tested in most $\mathrm{BC}$ and para-BC samples of $\mathrm{CHB}$ patients. High HBV DNA levels were detected in blood, while little HBV DNA was observed in the normal tissue of these patients. No HBV DNA was identified in the samples obtained from $\mathrm{HBV}^{-}$patients. HBV RNA, which is nearly nonexistent in HBV particles and is a marker of HBV replication, was also monitored via RT-qPCR (Fig. 5D). After gDNA elimination, extracted HBV RNA was reverse transcribed into cDNA and subjected to qPCR. All samples obtained from $\mathrm{HBV}^{-}$patients were HBV RNA-negative. Low copy numbers ( $<100$ copies) of HBV RNA were also determined in the blood samples and relatively normal tissues of CHB patients. Compared with the aforementioned samples, high copies of HBV RNA were detected in $\mathrm{BC}$ and para-BC tissues in 4 of the 10 patients with CHB. Furthermore, these results were significantly higher in $\mathrm{BC}$ tissues compared with para-BC tissues (Fig. 5D).
$H B V$ is detected in primary $B C$ cells derived from the $B C$ tissue of $C H B$ patients. $\mathrm{BC}$ primary cells were prepared from the $\mathrm{BC}$ tissues of $\mathrm{CHB}$ and $\mathrm{HBV}^{-}$patients as aforementioned. As presented in Fig. 6A, prepared primary cells were cultured in 6-well plates. After seeding for $24 \mathrm{~h}$, the cultured supernatant was discarded and suspensions of dead cells and potential viral particles from the tissue were removed by washing with PBS in triplicate. Anchorage-dependent cells were cultured continuously with fresh DMEM. As time passed, the isolated and cultured primary BC cells slowly propagated. Two cell strains at different time points were adopted as examples to be presented in Fig. 6B (upper panel, strain 1; lower panel, strain 2). HBs/eAg and HBV DNA in the supernatant and cell lysis samples at the indicated time points were assessed via ELISA and RT-qPCR as previously described (14). Compared with the primary $\mathrm{BC}$ cells derived from $\mathrm{HBV}^{-}$patients, $\mathrm{HBsAg}$ (Fig. 6C) in the supernatant and cell lysis samples, HBeAg (Fig. 6D) in the supernatant and HBV DNA (Fig. 6E) in the supernatant were all detected in the cultured primary BC cells 

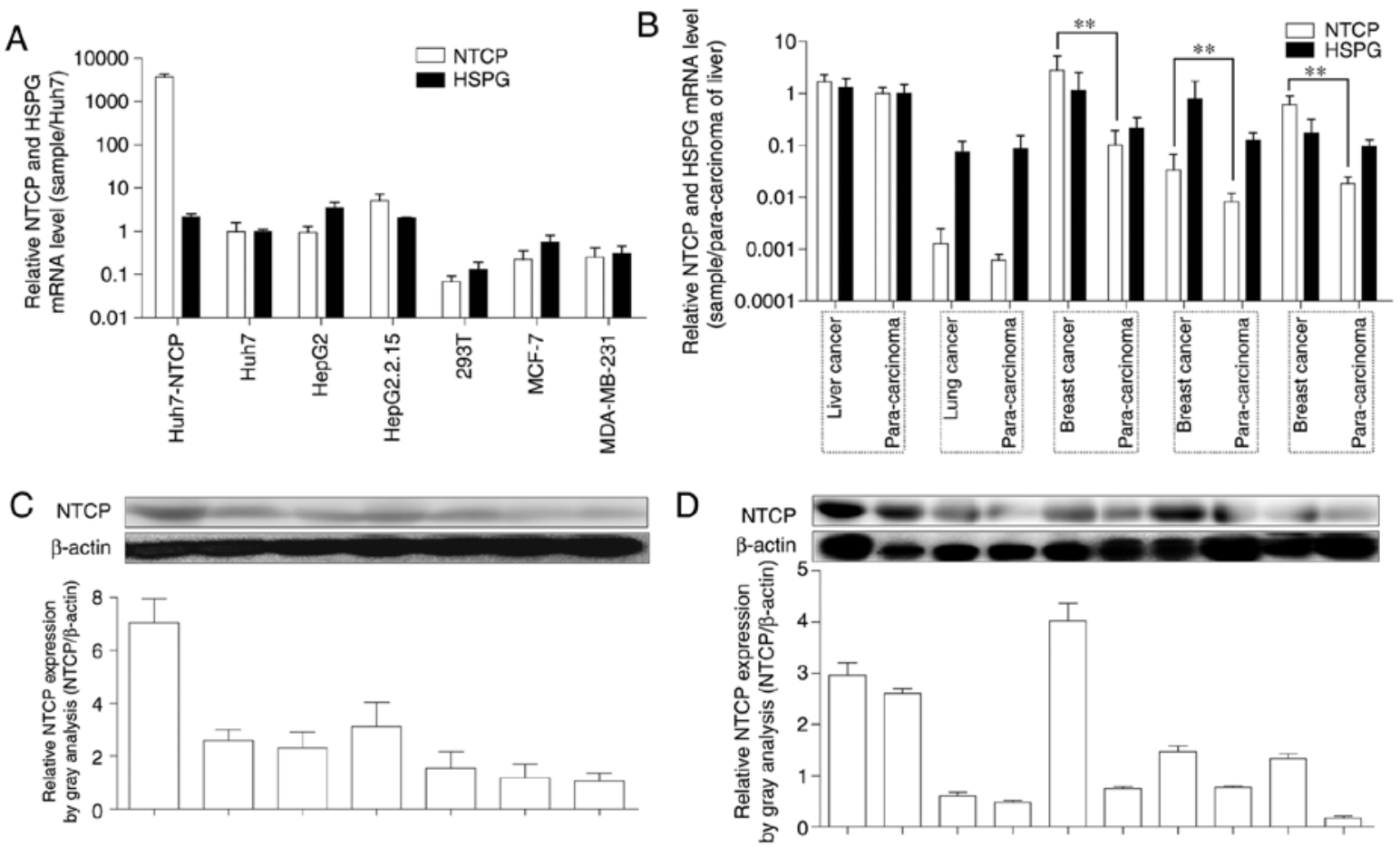

Figure 2. Expression of NTCP and HSPG in different cell lines, paired fresh frozen carcinoma and adjacent tissues. (A) NTCP and HSPG mRNA levels in different human cell lines were detected. (B) NTCP and HSPG in different carcinoma and adjacent tissues were detected at the transcriptional level. (C) Expression of NTCP in different human cell lines was analyzed via western blotting. (D) Expression of NTCP in different carcinoma and adjacent tissues was also detected via western blotting. ${ }^{* *} \mathrm{P}<0.01$, with comparisons indicated by brackets. NTCP, sodium taurocholate co-transporting polypeptide; HSPG, heparan sulfate proteoglycan.

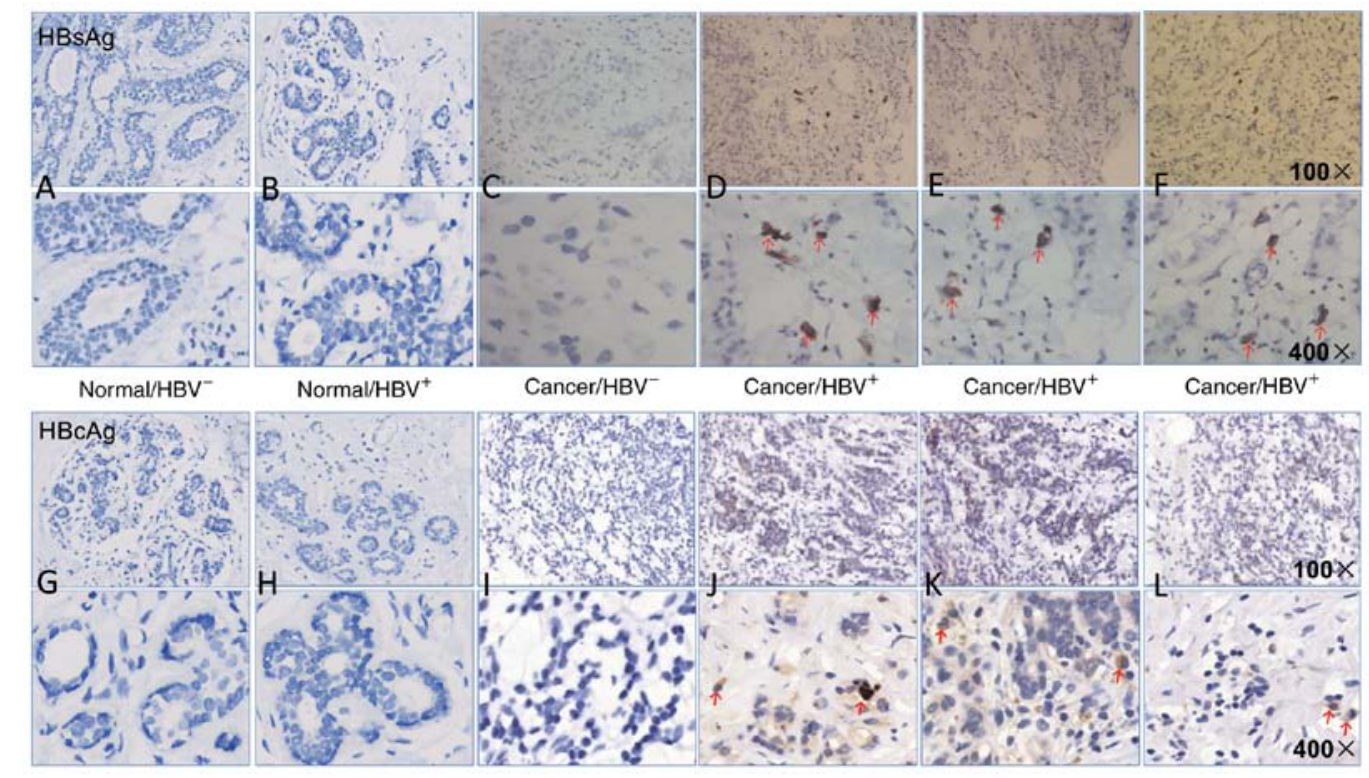

Figure 3. Immunohistochemical staining of $\mathrm{HBsAg}$ and hepatitis B core antigen $(\mathrm{HBcAg})$ in normal breast and $\mathrm{BC}$ tissues of $\mathrm{HBV}^{+/-}$patients. $(\mathrm{A}) \mathrm{HBs} \mathrm{Ag}$ expression in normal breast tissues from an $\mathrm{HBV}^{-}$patient. (B) Normal breast tissue from a $\mathrm{HBV}^{+}$patient. (C) $\mathrm{BC}$ tissue of a $\mathrm{HBV}^{-}$patient. $\mathrm{BC}^{\text {tissues of }}$ (D) $\mathrm{HBV}^{+}$patient I (E) $\mathrm{HBV}^{+}$patient II and (F) $\mathrm{HBV}^{+}$patient III were analyzed via immunohistochemical staining. $\mathrm{HBcAg}$ expression in the normal breast tissue of $(\mathrm{G})$ an $\mathrm{HBV}^{-}$patient and $(\mathrm{H})$ an $\mathrm{HBV}^{+}$patient. (I) $\mathrm{BC}$ tissue of an $\mathrm{HBV}^{-}$patient. BC tissues of $(\mathrm{J}) \mathrm{HBV}^{+}$patient I, (K) patient II and (L) patient III were also analyzed via immunohistochemistry. The upper and lower panels were imaged under a x100 and x400 lens, respectively. HBsAg, hepatitis B surface antigen; $\mathrm{HBV}$, hepatitis B virus; $\mathrm{BC}$, breast cancer.

of CHB patients. Furthermore, increasing quantities of HBV DNA markedly accumulated in the supernatant along with culture time, as presented in Fig. 6E. The results indicated the generation of progeny viruses.

\section{Discussion}

The increasing incidence of cancer and the associated mortality in recent years has made the disease a primary cause 

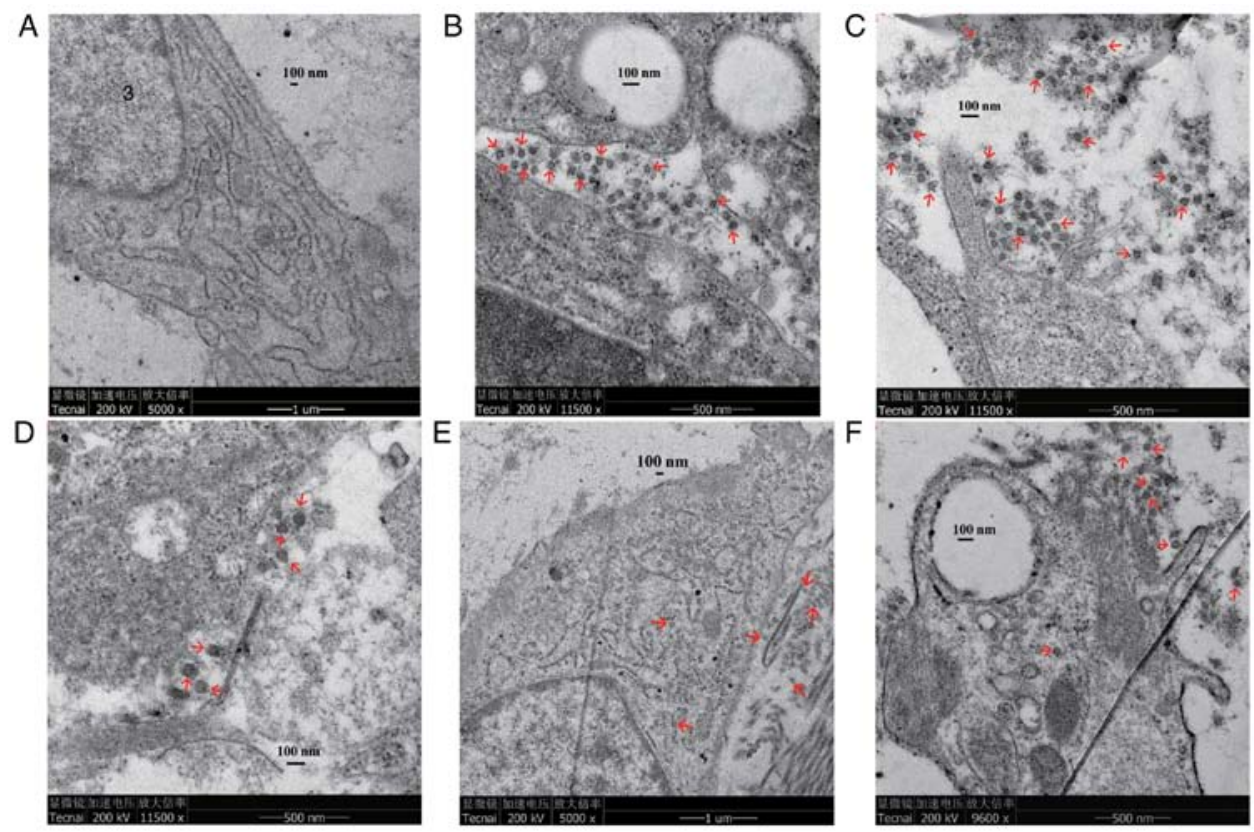

Figure 4. Electron microscopy of viral particles in BC tissues. (A) BC tissues from an $\mathrm{HBV}^{-}$patient, (B) $\mathrm{HBV}^{+}$patient I, (C) $\mathrm{HBV}^{+}$patient II, (D) $\mathrm{HBV}^{+}$patient III, (E) $\mathrm{HBV}^{+}$patient IV and $(\mathrm{F}) \mathrm{HBV}^{+}$patient $\mathrm{V}$ were collected and made into electron microscopic sections, which were visualized under a transmission electron microscope (Tecnai G2 F20 S-TWIN). Red arrows indicate possible HBV Dane particles (40-45 nm). BC, breast cancer; HBV, hepatitis B virus.

A

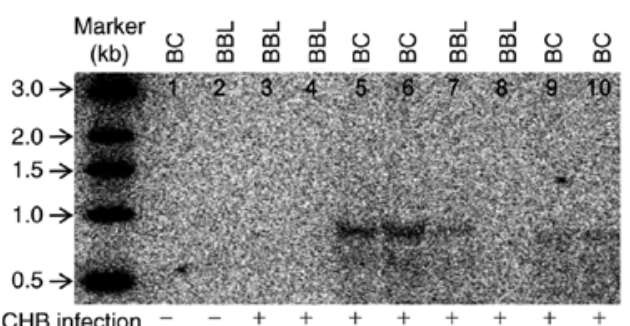

CHB infection

C

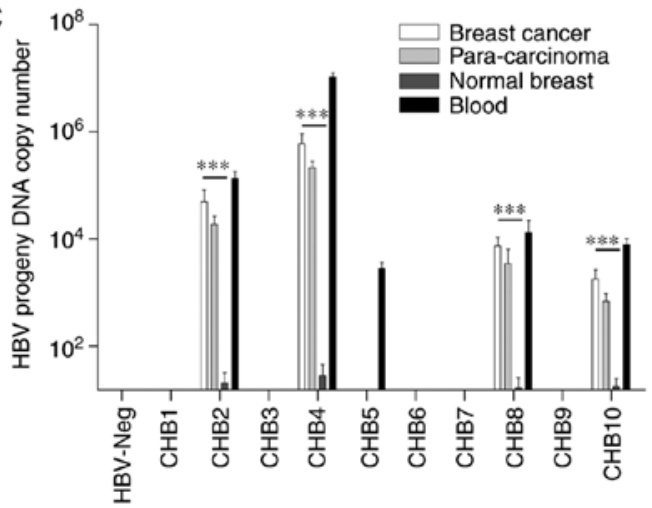

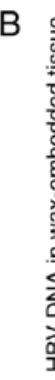
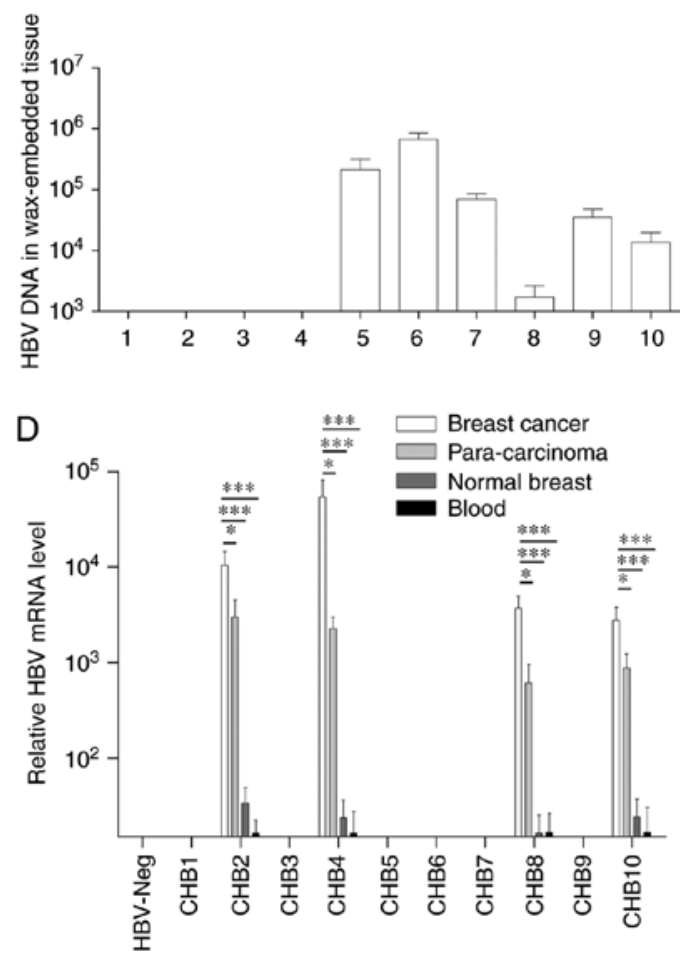

Figure 5. HBV DNA and RNA were detected in the BC tissues of CHB patients. HBV replication intermediates in wax blocks of BC and benign breast lumps were analyzed via (A) Southern blotting and (B) specific $\mathrm{qPCR}$, respectively. As shown in A, no HBV DNA was detected in the BC and BBL tissues of HBV patients (lane 1 and 2) or in the three BBLs of patients with CHB (lanes 3, 4 and 8). However, marked HBV replication was observed in four BC samples and one BBL sample of patients with CHB (lane 5,6,7,9 and 10). (C) HBV DNA was extracted from fresh BC tissues and blood samples of CHB or HBV patients, and subjected to qPCR. (D) HBV RNA, the marker of HBV replication, was extracted from fresh BC tissues and blood samples of CHB or HBV patients, and subjected to qPCR. " $\mathrm{P}<0.05$ and ${ }^{* * *} \mathrm{P}<0.001$, with comparisons indicated by lines. HBV, hepatitis $\mathrm{B}$ virus; $\mathrm{BC}$, breast cancer; $\mathrm{BBL}$, benign breast lump. qPCR, quantitative PCR; CHB, chronic hepatitis B.

of death and a major worldwide public health concern $(24,25)$. According to cancer statistics of 2015 , due to the large population base of China, $22 \%$ of all newly diagnosed cancer cases and $27 \%$ of global cancer-related deaths occur in China. Furthermore, a total of 3,120,000 new cancer cases and $>2,000,000$ cancer-related deaths occur in China every 
A Breast cancer tissue

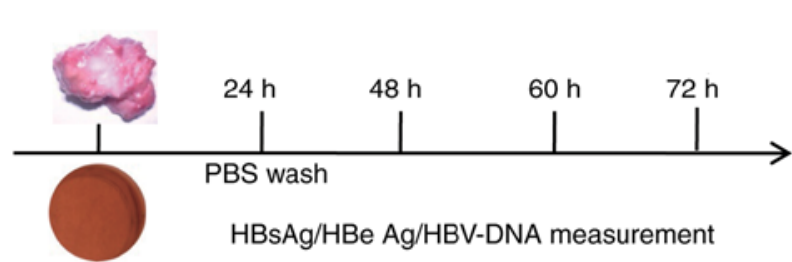

Primary breast cancer cells

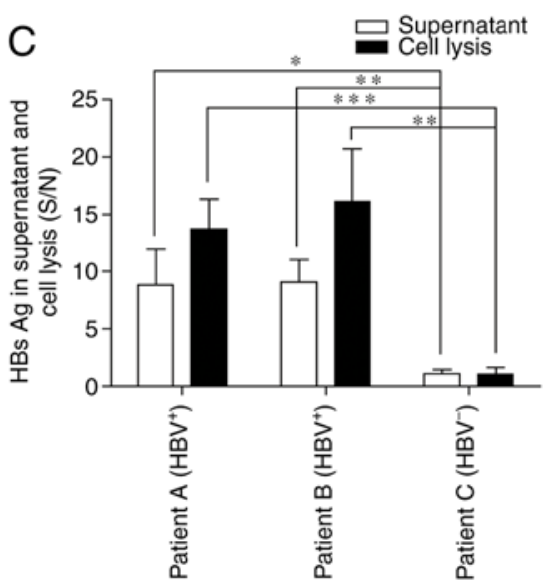

B

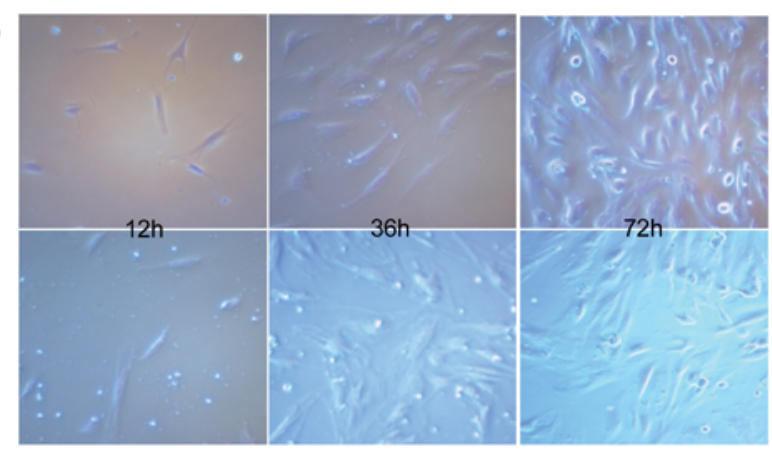

D

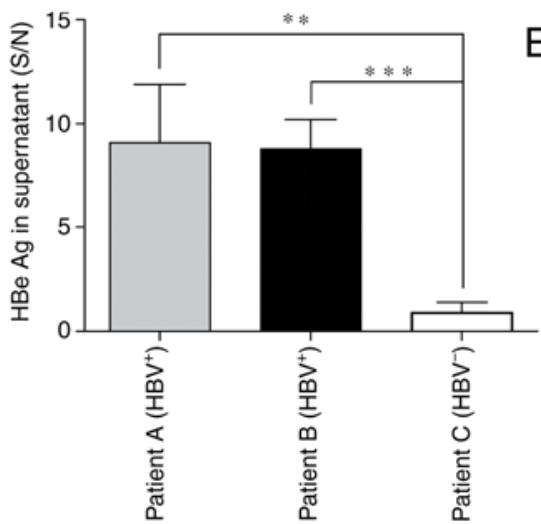

E

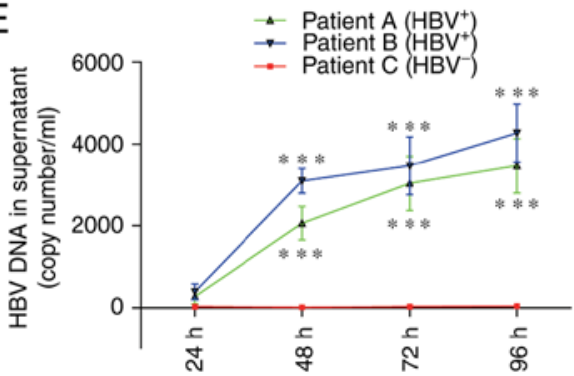

Figure 6. Continuous monitoring of HBV markers in primary $\mathrm{BC}$ cells derived from the BC tissues of $\mathrm{HBV}^{+/-}$patients. (A) Schematic of the experimental design to prepare primary cells of BC. (B) Cells were prepared, plated and cultured. Two cell strains at different time points were adopted as examples, as presented in the upper panel (strain 1) and the lower panel (strain 2). (C) HBsAg in the supernatant and cell lysis of cultured BC primary cells was measured via ELISA. (D) HBeAg in the supernatant of cultured BC primary cells was detected via ELISA. (E) HBV DNA in the supernatant of cultured BC primary cells at indicated time points was quantitatively determined via quantitative $\mathrm{PCR}$. ${ }^{*} \mathrm{P}<0.05,{ }^{* *} \mathrm{P}<0.01$ and ${ }^{* * *} \mathrm{P}<0.001$, with comparisons indicated by brackets. $\mathrm{HBV}$, hepatitis B virus; BC, breast cancer; HBsAg, hepatitis B surface antigen; HBeAg, hepatitis B e antigen; S/N, samples/negative.

year (26). In female malignant cancers, BC was found to be the leading one and the proportion was about $15 \%$ in China. Meanwhile, China is also a high occurrence region of $\mathrm{HBV}$ infection. Of the total Chinese population, $60 \%$ have been in contact with HBV and $7.2 \%$ are chronic carriers of HBsAg, as determined by laboratory testing $(27,28)$. Occult HBV infection is prevalent in Asia, ranging from 7.5-16\% (29). Especially in China, occult infection is common (30). Given that the incidence of $\mathrm{HBV}$ infection and $\mathrm{BC}$ are both high in China, it was hypothesized that $\mathrm{BC}$ patients co-infected with $\mathrm{HBV}$ are a common occurrence. HBV immunopathogenesis relies on a complex interplay of host and viral factors, including age, sex and immune status (2). Due to its unique genomic organization and replication strategy, HBV persists in the infected hepatocytes of patients for a long time (23).

HBV was discovered approximately 50 years ago and since then, important findings have been made. However, determining the mechanism of HBV infection and antiviral drug developments have been impeded by the lack of an effective and convenient viral infection model, due to the fact that the HBV cellular receptor was unknown (31). In the last few years, NTCP has been identified as the functional receptor of $\mathrm{HBV}$, which has allowed for the study of the HBV life cycle, the development of an in vivo and in vitro HBV infection model and the development of new antiviral agents $(5,6)$. Together with NTCP, HSPG in the Disse gap space of the liver also serves an essential role in HBV and
HDV infection. It is thought to bring viral particles in close proximity to NTCP prior to specific attachment between $\mathrm{HBV}$ and its receptors (5).

$\mathrm{HBV}$ is a member of the liver tropic virus family and as such, the liver was considered to be the only target organ for HBV infection and replication (32). Cellular receptors were also considered to contribute to the liver tropism and species specificity of HBV infections (33). Although NTCP has been identified as an entry receptor of HBV and HDV, additional unidentified host factors may remain. The present study revealed that NTCP is highly expressed in BC, both via Oncomine database analysis and clinical specimen identification. NTCP was found to be highly expressed in the liver, but was weaker in primary human hepatocytes cultured in vitro. This may be the reason why the expression of NTCP in certain BC cell lines, including MCF7 and MDA-MB-231, was not as high as those in fresh BC tissues. To assess the biological significance of high NTCP expression in $\mathrm{BC}$, all markers of $\mathrm{HBV}$ were detected in the BC tissues of chronic HBV (CHB) patients. HBV and HDV coinfection is considered the most severe form of viral hepatitis. HDV, one type of defective virus, is HBV's satellite virus; it is unable to complete its life cycle on its own. Thus, in the present study, we mainly focused on HBV. We aimed to ascertain the relationship between HBV, NTCP and BC. In future research, we will also investigate $\mathrm{HDV}$, trying to assess whether HDV can infect BC. 
NTCP is a translocator of cholate. Cholate metabolism not only takes place in the liver, but also in other organs. In our study, the Oncomine database was used to explore the NTCP expression difference in many types of cancer and normal tissues. Notably, NTCP was upregulated in BC. Liver was traditionally thought to be the sole target of HBV and HDV. Entry-level barrier, special atmosphere of the human liver and various unknown reasons prevent cross-species and cross-liver infection of HBV. We wondered why NTCP expression is high in $\mathrm{BC}$, and whether HBV can infect BC. Thus, BC was selected for further study.

In $\mathrm{BC}$ tissues of $\mathrm{CHB}$ patients, high expression levels of HBs, HBc and HBV DNA were detected. Complete and incomplete viral particles are found in the blood samples of CHB patients. Complete viral particles contain an outer envelope and an inner icosahedral nucleocapsid, which is assembled by 240 copies of $\mathrm{HBc}$ and packaged with a 3.2-kb HBV DNA genome (34). An incomplete viral particle includes an HBsAg particle, an empty virion and a naked capsid, the latter of which is either empty or filled with HBV RNA and/or immature DNA (35). In the present study, a high load of HBV RNA generated during replication was detected in the BC and para-BC tissues of the $\mathrm{CHB}$ patients. However, HBV RNA was rarely detected in the blood samples of patients with a high HBV viral load. For further verification, primary $\mathrm{BC}$ cells were acquired from the $\mathrm{BC}$ tissues of $\mathrm{CHB}$ patients and cultured in the same way as commonly performed in other cell lines, including MCF-7 and MDA-MB-231. HBs/e antigen production and secretion, and a continuous increase of HBV DNA was detected in the cultured supernatants of primary $\mathrm{BC}$ cells from HBV-positive patients. However, these $\mathrm{HBV}$ markers were absent in the primary BC cells of $\mathrm{HBV}^{-}$patients. NTCP mRNA and protein levels were low in normal breast tissue, as upregulation would only occur with breast tumorigenesis, which was in line with our previous data. The results of the present study indicate that $\mathrm{HBV}$ infects BC by binding to NTCP on the surface of BC cells, where the virus subsequently replicates. Owing to a lack of proofreading capacity during reverse transcription and a high replication rate, $\mathrm{HBV}$ exists as a quasispecies, which implies a spectrum of mutants that possess different fitness levels in certain environments. Mutants with higher fitness levels may predominate by competitive replication. In the present study, extrahepatic infection of HBV was assessed. We did not allow for mutation, sequence and anti-HBV therapy. But in subsequent research, it will be important to analyze the sequence alignment between $\mathrm{BC}$, blood and liver.

HBV is not cytopathic for infected hepatocytes, but the immune response to persistent viral infection causes liver injury $(36,37)$. Incorporating the HBV genome into that of the host leads to increased cell growth or the disruption of gene expression, which consequently affects liver cell division and differentiation (36). HBV-triggered immune responses and liver injury serve important roles in the onset and spread of liver cancer (36). The inactivation of estrogen was revealed to be significantly influenced by HBV-associated hepatic injury (38) and high levels of estrogen are associated with BC (39).

The present study demonstrated that HBV successfully infects BC tissue. This result will require further research including the determination of whether HDV, as a satellite virus of $\mathrm{HBV}$, infects $\mathrm{BC}$ tissues. As another $\mathrm{HBV}$ repository in addition to the liver, the role that HBV serves in the occurrence and development of $\mathrm{BC}$ will require further elucidation. Furthermore, due to the additional target organ of HBV, the impact of this on HBV replication will require attention. Whether anti-HBV therapy for CHB patients affects BC also requires future study. The present study may initiate a new field of science, in which the molecular mechanisms of HBV infection and replication in $\mathrm{BC}$ and the association between $\mathrm{HBV}$ infection and $\mathrm{BC}$ can be elucidated. The results of the present study may also bring new challenges to the prevention and treatment of $\mathrm{HBV}$ infection and $\mathrm{BC}$, and provide a new target for overcoming them.

\section{Acknowledgements}

Not applicable.

\section{Funding}

This work was supported by the National Natural Science Foundation of China (grant no. 81772537), Foundation of Zhejiang Province Medical Health (grant no. 2020357743), Foundation of Shaoxing Municipal Commission of Health and Family Planning (CN), Zhejiang Province of China (grant no. 2017QN001), and Shaoxing Municipal Science and Technology Commission, Zhejiang Province of China (grant no. 2017B70022).

\section{Availability of data and materials}

The datasets used during the present study are available from the corresponding author upon reasonable request.

\section{Authors' contributions}

BQ designed the research. BQ, KZ, JW, XW, MX, JL, HS and $\mathrm{KJ}$ conducted the research and carried out the experiments. BQ analyzed the data and wrote the paper. All authors read and approved the manuscript and agree to be accountable for all aspects of the research in ensuring that the accuracy or integrity of any part of the work are appropriately investigated and resolved. All authors contributed significantly to this study.

\section{Ethics approval and consent to participate}

Patient informed consent was provided for all samples used in the study. The present study was conducted in compliance with the ethical guidelines of the 1975 Declaration of Helsinki and was approved by the Ethics Committee of Shaoxing People's Hospital (2019 Ethics clearance no. 03).

\section{Patient consent for publication}

Not applicable.

\section{Competing interests}

The authors declare that they have no competing interests. 


\section{References}

1. Ramírez-Soto MC, Ortega-Cáceres G and Cabezas C: Trends in mortality burden of hepatocellular carcinoma, cirrhosis, and fulminant hepatitis before and after roll-out of the first pilot vaccination program against hepatitis B in Peru: An analysis of death certificate data. Vaccine 35: 3808-3812, 2017.

2. World Health Organization: Hepatitis B vaccines: WHO position paper, July 2017-Recommendations. Vaccine 37: 223-225, 2019.

3. Fairman J, Liu KH and Menne S: Prevention of liver tumor formation in woodchucks with established hepatocellular carcinoma by treatment with cationic liposome-DNA complexes. BMC Cancer 17: 172, 2017.

4. Qin B, Zhou Y, Zhou G, Xu X, Wang Y and Chen J: Substitutions of rtL228 and/or L229 are involved in the regulation of replication and HBsAg secretion in hepatitis B virus, and do not affect susceptibility to nucleos(t)ide analogs. Mol Med Rep 16: 9678-9684, 2017

5. Li W: The hepatitis B virus receptor. Annu Rev Cell Dev Biol 31: $125-147,2015$.

6. Yan $\mathrm{H}$ and Li W: Sodium taurocholate cotransporting polypeptide acts as a receptor for hepatitis B and D virus. Dig Dis 33: 388-396, 2015.

7. Ni Y, Lempp FA, Mehrle S, Nkongolo S, Kaufman C, Fälth M, Stindt J, Königer C, Nassal M, Kubitz R, et al: Hepatitis B and D viruses exploit sodium taurocholate co-transporting polypeptide for species-specific entry into hepatocytes. Gastroenterology 146: 1070-1083, 2014

8. Zhou M, Zhao K, Yao Y, Yuan Y, Pei R, Wang Y, Chen J, $\mathrm{Hu} X$, Zhou Y, Chen X and Wu C: Productive HBV infection of well-differentiated, hNTCP-expressing human hepatoma-derived (Huh7) cells. Virol Sin 32: 465-475, 2017.

9. He W, Ren B, Mao F, Jing Z, Li Y, Liu Y, Peng B, Yan H, Qi Y, Sun Y, et al: Hepatitis D virus infection of mice expressing human sodium taurocholate co-transporting polypeptide. PLoS Pathog 11: e1004840, 2015.

10. Blank A, Markert C, Hohmann N, Carls A, Mikus G, Lehr T, Alexandrov A, Haag M, Schwab M, Urban S and Haefeli WE: First-in-human application of the novel hepatitis B and hepatitis D virus entry inhibitor myrcludex B. J Hepatol 65: 483-489, 2016.

11. Kaneko M, Watashi K, Kamisuki S, Matsunaga H, Iwamoto M, Kawai F, Ohashi H, Tsukuda S, Shimura S, Suzuki R, et al: A Novel tricyclic polyketide, Vanitaracin A, specifically inhibits the entry of hepatitis B and D viruses by targeting sodium taurocholate cotransporting polypeptide. J Virol 89: 11945-11953, 2015.

12. De Meyer S, Gong ZJ, Suwandhi W, van Pelt J, Soumillion A and Yap SH: Organ and species specificity of hepatitis B virus (HBV) infection: A review of literature with a special reference to preferential attachment of HBV to human hepatocytes. J Viral Hepat 4: 145-153, 1997.

13. Xu X, Yan Q, Wang Y and Dong X: NTN4 is associated with breast cancer metastasis via regulation of EMT-related biomarkers. Oncol Rep 37: 449-457, 2017.

14. Qin B, Budeus B, Cao L, Wu C, Wang Y, Zhang X, Rayner S, Hoffmann D, Lu M and Chen X: The amino acid substitutions $\mathrm{rtP} 177 \mathrm{G}$ and $\mathrm{rtF} 249 \mathrm{~A}$ in the reverse transcriptase domain of hepatitis B virus polymerase reduce the susceptibility to tenofovir. Antiviral Res 97: 93-100, 2013.

15. Esparza-López J, Ramos-Elías PA, Castro-Sánchez A, Rocha-Zavaleta L, Escobar-Arriaga E, Zentella-Dehesa A, León-Rodríguez E, Medina-Franco H and Ibarra-Sánchez MJ: Primary breast cancer cell culture yields intra-tumor heterogeneous subpopulations expressing exclusive patterns of receptor tyrosine kinases. BMC Cancer 16: 740, 2016.

16. Naipal KA, Verkaik NS, Sánchez H, van Deurzen $\mathrm{CH}$ den Bakker MA, Hoeijmakers JH, Kanaar R, Vreeswijk MP, Jager A and van Gent DC: Tumor slice culture system to assess drug response of primary breast cancer. BMC Cancer 16: 78, 2016.

17. Huang Y, Burns DJ, Rich BE, MacNeil IA, Dandapat A, Soltani SM, Myhre S, Sullivan BF, Lange CA, Furcht LT and Laing LG: Development of a test that measures real-time HER2 signaling function in live breast cancer cell lines and primary cells. BMC Cancer 17: 199, 2017.

18. Yu XJ, Liang MF, Zhang SY, Liu Y, Li JD, Sun YL, Zhang L, Zhang QF, Popov VL, Li C, et al: Fever with thrombocytopenia associated with a novel bunyavirus in China. N Engl J Med 364 $1523-1532,2011$
19. Santos AP, Levi JE, Lemos MF, Calux SJ, Oba IT and Moreira RC: An in-house real-time polymerase chain reaction: Standardisation and comparison with the Cobas Amplicor HBV monitor and Cobas AmpliPrep/Cobas TaqMan HBV tests for the quantification of hepatitis B virus DNA. Mem Inst Oswaldo Cruz 111: 134-140, 2016.

20. Salpini R, Piermatteo L, Gill U, Battisti A, Stazi F, Guenci T, Giannella S, Serafini V, Kennedy PTF, Perno CF, et al: Quantification of intrahepatic total HBV DNA in liver biopsies of HBV-infected patients by a modified version of COBAS ${ }^{\circledR}$ Ampliprep/COBAS ${ }^{\circledR}$ TaqMan HBV test v2.0. Med Microbiol Immunol 206: 295-299, 2017.

21. Kohls K, Schmidt D, Holdenrieder S, Müller SC and Ellinger J: Detection of cell-free lncRNA in serum of cancer patients. Urologe A 54: 819-825, 2015 (In German).

22. Hayes CN, Zhang Y, Makokha GN, Hasan MZ, Omokoko MD and Chayama K: Early events in hepatitis B virus infection: From the cell surface to the nucleus. J Gastroenterol Hepatol 31: 302-309, 2016

23. Pei R, Qin B, Zhang X, Zhu W, Kemper T, Ma Z, Trippler M, Schlaak J, Chen X and Lu M: Interferon-induced proteins with tetratricopeptide repeats 1 and 2 are cellular factors that limit hepatitis B virus replication. J Innate Immun 6: 182-191, 2014.

24. Helgstrand JT, Røder MA, Klemann N, Toft BG, Lichtensztajn DY, Brooks JD, Brasso K, Vainer B and Iversen P: Trends in incidence and 5-year mortality in men with newly diagnosed, metastatic prostate cancer-A population-based analysis of 2 national cohorts. Cancer 124: 2931-2938, 2018.

25. Bray F, Ferlay J, Soerjomataram I, Siegel RL, Torre LA and Jemal A: Global cancer statistics 2018: GLOBOCAN estimates of incidence and mortality worldwide for 36 cancers in 185 countries. CA Cancer J Clin 68: 394-424, 2018.

26. Chen W, Zheng R, Baade PD, Zhang S, Zeng H, Bray F, Jemal A, Yu XQ and He J: Cancer statistics in China, 2015. CA Cancer J Clin 66: 115-132, 2016.

27. Lin BL, Chen JF, Qiu WH, Wang KW, Xie DY, Chen XY, Liu QL, Peng L, Li JG, Mei YY, et al: Allogeneic bone marrow-derived mesenchymal stromal cells for hepatitis B virus-related acute-on-chronic liver failure: A randomized controlled trial. Hepatology 66: 209-219, 2017.

28. Wei XL, Qiu MZ, Chen WW, Jin Y, Ren C, Wang F, Luo HY, Wang ZQ, Zhang DS, Wang FH, et al: The status of HBV infection influences metastatic pattern and survival in Chinese patients with pancreatic cancer. J Transl Med 11: 249, 2013.

29. Morales-Romero J, Vargas G and García-Román R: Occult HBV infection: A faceless enemy in liver cancer development. Viruses 6: 1590-1611, 2014.

30. Tajima K, Takahashi N, Ishizawa K, Murai K, Akagi T, Noji H, Sasaki O, Wano M, Itoh J, Kato Y, et al: Tohoku Hematology Forum: High prevalence of diffuse large B-cell lymphoma in occult hepatitis B virus-infected patients in the Tohoku district in Eastern Japan. J Med Virol 88: 2206-2210, 2016.

31. Yan H, Liu Y, Sui J and Li W: NTCP opens the door for hepatitis B virus infection. Antiviral Res 121: 24-30, 2015.

32. Bility MT, Li F, Cheng L and Su L: Liver immune-pathogenesis and therapy of human liver tropic virus infection in humanized mouse models. J Gastroenterol Hepatol 28 (Suppl 1): S120-S124, 2013.

33. Watashi $\mathrm{K}$ and Wakita T: Hepatitis B virus and hepatitis D virus entry, species specificity, and tissue tropism. Cold Spring Harb Perspect Med 5: a021378, 2015.

34. Summers J and Mason WS: Replication of the genome of a hepatitis B-like virus by reverse transcription of an RNA intermediate. Cell 29: 403-415, 1982.

35. Bai L, Zhang X, Kozlowski M, Li W, Wu M, Liu J, Chen L, Zhang J, Huang Y and Yuan Z: Extracellular hepatitis B virus RNAs are heterogeneous in length and circulate as capsid-antibody complexes in addition to virions in chronic hepatitis B patients. J Virol 92: e00798-18, 2018.

36. Dandri M and Locarnini S: New insight in the pathobiology of hepatitis B virus infection. Gut 61 (Suppl 1): i6-i17, 2012.

37. Nakamoto $\mathrm{Y}$ and Kaneko S: Mechanisms of viral hepatitis induced liver injury. Curr Mol Med 3: 537-544, 2003.

38. Liu WC and Liu QY: Molecular mechanisms of gender disparity in hepatitis B virus-associated hepatocellular carcinoma. World J Gastroenterol 20: 6252-6261, 2014.

39. Suba Z: Circulatory estrogen level protects against breast cancer in obese women. Recent Patents Anticancer Drug Discov 8: 154-167, 2013. 